\title{
OPINION
}

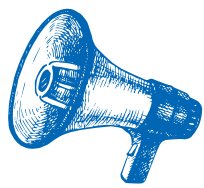

\section{MathJobs at the University of California-R.I.P.}

\section{Abigail Thompson}

Note: The opinions expressed here are not necessarily those of Notices.

MathJobs for faculty hiring is dead at the University of California (UC), killed by the UC administration. This is a brief history of what happened, some conjectures as to why, and how optimists might try to avoid its demise at other institutions.

\section{What happened}

The department chairs in each UC math department were notified in April of 2018 that as of July 1, 2018 all mathematics department faculty recruitments would be run through UC Recruit, the University of California's inhouse job application system. Within a week the chairs of mathematics of eight UC campuses wrote a joint letter in protest to the University of California Council of Executive Vice-Chancellors, the system-wide decision-making body behind this process. This letter made the obvious points that the decision would put UC at a competitive disadvantage with respect to other institutions in mathematics hiring, enormously increase the workload both for applicants and reference letter writers, force UC faculty to use a cumbersome and inefficient system, and have a serious negative impact on UC's ability to attract a diverse applicant pool.

Abigail Thompson is a professor in and the chair of the Department of Mathematics at the University of California, Davis. She is also a vice president of the AMS. Her email address is thompson@math. ucdavis. edu.

For permission to reprint this article, please contact: reprint-permission aams.org.

DOI: https://dx.doi.org/10.1090/noti1911
By early May the chairs had received no response to the concerns raised in their letter; they were simply informed that UC was going ahead with the move to the new system. In late May, the department chairs together with more than 270 UC mathematics faculty from eight campuses signed a letter of protest and sent it to UC President Janet Napolitano. Various individual UC mathematics faculty and faculty committees also sent letters of protest to President Napolitano. One suggestion for compromise that was made at this time (following consultation with the MathJobs team at the AMS) was that it should be possible to coordinate the two systems so that applications and reference letters would automatically be fed from MathJobs to UC Recruit. After considerable further correspondence, consultation with some Executive Vice-Chancellors, and a demonstration of MathJobs to UC Vice Provost Susan Carlson and the UC Recruit team and Governing Board, in July the chairs received a reply offering a glimmer of hope. They heard from UC Provost Michael T. Brown that, while the decision to move to UC Recruit was final, the process of coordinating the "necessary analysis of a technical connection between the two systems" would begin. In the next few months, some consultation on ways to improve UC Recruit was conducted, but coordination and consultation on data transfer between MathJobs and UC Recruit was postponed. In December 2018, the chairs were told, "UC has decided that our best option in future years is to use the UC Recruit as the basis of our recruitments in mathematics...UC will not be pursuing a technical feed between the two systems." 
Here are some important notes: Several other universities and programs already automatically download data from MathJobs to their own institutional systems (see https:// academicjobson 1 ine.org/ajo/intro for a quote from the Institute for Advanced Study). There are various levels of data transfer possible from MathJobs, ranging from the maximal: (a) transfer (and updating) of entire applications, including reference letters, to the minimal: (b) automatic transfer of letters of recommendation. For (a), while data transfer is easy according to the technical team at MathJobs, the main difficulty is in treating incoming data in a way that is consistent with local institutional practices designed to meet legal requirements, particularly if the applicant revises their file. This does require cooperation on the part of the institution to which information is being transferred. However, MathJobs can be tailored to create a version (via settings) that clones an institution's practices; then at appropriate times data can automatically transfer. On the other hand, implementing (b) is very easy on all counts, as data transfer and institutional rules for handling letters of recommendation are straightforward to incorporate. While this would not save applicants from having to apply in a different system, it would save an enormous overhead for reference letter writers.

The UC mathematics departments engaged in extensive efforts to facilitate some form of automatic data transfer. In this, the MathJobs team at the AMS and the AMS leadership (especially then-President Ken Ribet, who met with Carlson and Brown in June 2018) were extremely helpful, and by all accounts were eager, willing, and able to help facilitate a technical solution. In contrast, the University of California administration ultimately declined even to commit the minimal effort required for (b), and their idea of "consultation" appeared to be along the lines of asking "how can we make UC Recruit work better for you?"

Another point, and the reason for the history recital, is that I can't think of anything more we could have tried. UC mathematicians were united, vocal, active, open to compromise, and anxious for a solution. None of that seemed to matter. Effectively, once the edict was handed down, the decision had been made.

\section{Why this happened}

So why was this decision made, and apparently immediately carved in stone? Mathematicians had developed and run a terrific tool for job applications for years. Why couldn't they leave us alone?

The ostensible reasons have to do with compliance with state and federal law. In a letter from May 2018, UC Vice Provost Susan Carlson, who spearheaded the move to UC Recruit, said, "...the benefits of the move to UC Recruit, particularly bringing UC into compliance with California and Federal recruitment standards, outweigh the negative consequences...." This compliance issue makes no sense, and this assertion was never supported; MathJobs can be set to have almost any kind of desired data collection and any needed privacy and compliance settings.

I believe that one reason for the extraordinary obstinacy is related to the alarming trend of increasing administrative control over faculty hiring at the University of California. More and more faculty positions are in some "special" category controlled largely by administrators; departments starved for faculty can select from a pool of pre-screened applicants or else get no one at all. In short, UC Recruit ensures that the administration now will have first crack at filtering the files.

Another possible factor is UC Vice Provost Susan Carlson's special interest in the potential uses of the UC Recruit system. From the abstract of her \$1.18 million 2015-19 NSF grant (\#1535509), which aims to address the questions "are there gender and racial/ethnic disparities in STEM faculty hiring? If so, what conditions, processes and social contexts generate/mitigate these disparities?", we see that the PIs "will construct and use a unique dataset from an online administrative system that compiles information from all faculty recruitments at all University of California campuses. This rich data source includes detailed information on applicant pools, applicant credentials and achievements, hiring processes and committees, and candidates' progression from application through the short list, interview, and offer steps in the process." While this is perhaps an interesting research project, it is hard to see why UC mathematics faculty should be compelled to participate.

It is especially ironic that the implementation of UC Recruit will override the most efficient mechanism for actually promoting diversity in mathematics faculty hiring, namely using MathJobs for faculty recruitment to ensure the most inclusive possible pool.

\section{How to fight against this}

I see no reason for optimism. The only effective way I've heard of to counter this in the long term has unacceptable consequences in the short term; one could simply refuse to post letters of recommendation anywhere except on MathJobs. Several mathematicians have in fact adopted this policy. The difficulty is that the short-term damage would be to job applicants, the people whom we most wish to support. So I can't advocate for this position.

If, or more likely when, an attack on MathJobs arises at your own institution, here are some things that may be helpful to know:

- It is possible for files/letters to be imported from MathJobs to an in-house system, and the AMS and MathJobs are interested in and experienced at making this work.

- The claim that the use of an in-house system is essential to ensure compliance with state and federal laws appears to be totally specious. There was no supporting documentation ever offered for this claim, and no credible reason that using MathJobs should be problematic. 
- Most faculty outside of mathematics have no idea what we are talking about. Faculty searches in other disciplines are often highly focused and have relatively small applicant pools. Faculty members in other disciplines typically spend endless hours posting letters of recommendation to tediously contrived individual university portals, and job applicants spend even more time doing the same. While we are all experienced with the nightmare of dealing with letters of recommendation for our undergraduate students applying to multiple graduate programs ("please rate the candidate on the following seventeen largely irrelevant characteristics..."), in many disciplines this incredibly inefficient and annoying process has long been the norm for job applicants as well. People in other fields don't really see why we shouldn't suffer, too.

\section{Conclusion}

At the beginning of this century, mathematicians developed and implemented an effective system for online job university administrators quite a few years to get around to trying to destroy this system, but they are really making an effort. I am afraid we soon will all be back to the endless uploading of reference letters and the equally frustrating task of submitting individual job applications. I can't see a way out of this quagmire; perhaps others will find a path.

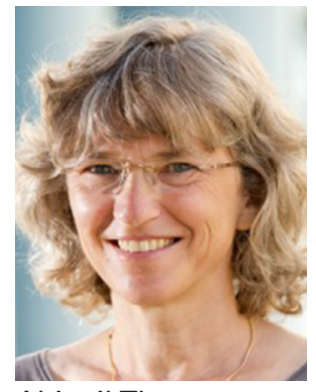

Abigail Thompson

\section{Credits}

Author photo is courtesy of University of California, Davis. applications that was way ahead of its time. It has taken

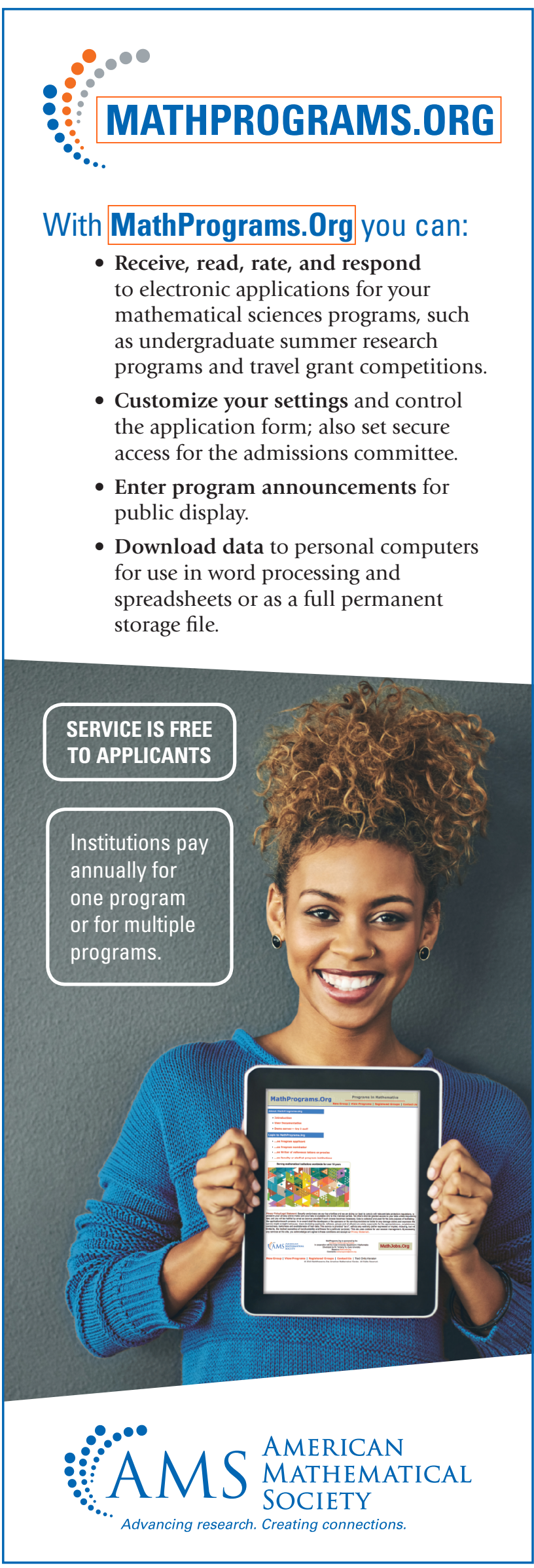

